\title{
Biowaiver Monographs for Immediate Release Solid Oral Dosage Forms: Pyrazinamide
}

\author{
C. BECKER, ${ }^{1}$ J.B. DRESSMAN, ${ }^{1}$ G.L. AMIDON, ${ }^{2}$ H.E. JUNGINGER, ${ }^{3}$ S. KOPP, ${ }^{4}$ K.K. MIDHA, \\ V.P. SHAH, ${ }^{6}$ S. STAVCHANSKY, ${ }^{7}$ D.M. BARENDS ${ }^{8}$ \\ ${ }^{1}$ Institute of Pharmaceutical Technology, J.W. Goethe University, Frankfurt, Germany \\ ${ }^{2}$ College of Pharmacy, University of Michigan, Ann Arbor, Michigan \\ ${ }^{3}$ Faculty of Pharmaceutical Sciences, Naresuan University, Phitsanulok, Thailand \\ ${ }^{4} \mathrm{WHO}-$ World Health Organization, Geneva, Switzerland \\ ${ }^{5}$ University of Saskatchewan, Saskatoon, Saskatchewan, Canada \\ ${ }^{6}$ International Pharmaceutical Federation FIP, The Hague, The Netherlands \\ ${ }^{7}$ Pharmaceutical Division, College of Pharmacy, University of Texas at Austin, Austin, Texas \\ ${ }^{8}$ RIVM - National Institute for Public Health and the Environment, Bilthoven, The Netherlands
}

Received 7 August 2007; revised 17 October 2007; accepted 17 October 2007

Published online in Wiley InterScience (www.interscience.wiley.com). DOI 10.1002/jps.21250

\begin{abstract}
Literature data relevant to the decision to allow a waiver of in vivo bioequivalence (BE) testing for the approval of immediate release (IR) solid oral dosage forms containing pyrazinamide as the only active pharmaceutical ingredient (API) are reviewed. Pyrazinamide is BCS Class III, with linear absorption over a wide dosing range. The risk of bioinequivalence is estimated to be low. Depending on the definition used, pyrazinamide can be classified as a narrow therapeutic index (NTI) drug, which is usually a caveat to biowaiving but may be deemed acceptable if the Summary of Product Characteristics (SmPCs) of the test product stipulates the need for regular monitoring of liver function. It is concluded that a biowaiver can be recommended for IR solid oral dosage only when the test product (a) contains only excipients present in pyrazinamide IR solid oral drug products approved in ICH or associated countries, (b) these excipients are present in amounts normally used in IR solid oral dosage forms, (c) the test product is very rapidly dissolving, (d) the SmPC of the test product indicates the need for monitoring of the patient's liver function. (c) 2008 Wiley-Liss, Inc. and the American Pharmacists Association J Pharm Sci 97:3709-3720, 2008
\end{abstract}

Keywords: absorption; bioequivalence; biopharmaceutics classification system (BCS); dissolution; permeability; pyrazinamide; regulatory science; solubility

A project of the International Pharmaceutical Federation FIP, Groupe BCS, www.fip.org/bcs.

This article reflects the scientific opinion of the authors and not the policies of regulating agencies.

Correspondence to: D.M. Barends (Telephone: 31-302744209; Fax: 31-30-2744462; E-mail: dirk.barends@rivm.nl)

Journal of Pharmaceutical Sciences, Vol. 97, 3709-3720 (2008)

(c) 2008 Wiley-Liss, Inc. and the American Pharmacists Association

\section{INTRODUCTION}

A biowaiver monograph of pyrazinamide based on literature data together with some additional experimental data is presented. The risks of basing a bioequivalence (BE) assessment on in vitro rather than in vivo study results for the approval of new immediate release (IR) solid oral 
dosage forms containing pyrazinamide ("biowaiving"), including both reformulated products and new multisource drug products, are evaluated under consideration of its biopharmaceutical and clinical properties. This evaluation refers to drug products containing pyrazinamide as the only active pharmaceutical ingredient (API) and not to combination products.

The purpose and scope of this series of monographs have been previously discussed. ${ }^{1}$ Summarized in few words, the aim is to evaluate all pertinent data available from literature sources for a given API to assess the risks associated with a biowaiver. For these purposes, risk is defined as the probability of an incorrect biowaiver decision as well as the consequences of the decision in terms of public health and individual patient risks. On the basis of these considerations, a recommendation can be made as to whether a biowaiver approval is advisable or not. This systematic approach to recommend or advise against a biowaiver decisions is referred to in the recently published World Health Organization (WHO) Guideline. ${ }^{2}$ It is pointed out that these monographs do not simply apply this WHO Guideline, nor the FDA and/or EMEA Guidance, but also want to serve as a critical validation of these regulatory documents. Biowaiver monographs have already been published for acetaminophen (INN: paracetamol), ${ }^{3}$ amitriptyline, ${ }^{4}$ atenolol, ${ }^{1}$ chloroquine,${ }^{5}$ cimetidine ${ }^{6}$ ethambutol, ${ }^{7}$ ibuprofen, ${ }^{8}$ isoniazid, ${ }^{9}$ prednisolone, ${ }^{10}$ prednisone ${ }^{11}$ propranolol, ${ }^{1}$ ranitidine, ${ }^{12}$ and verapamil. ${ }^{1}$ They are also available online at the website of the International Pharmaceutical Federation FIP. ${ }^{13}$

\section{EXPERIMENTAL}

Literature data from PubMed, ${ }^{14}$ PubChem, ${ }^{15}$ Medicines Complete, ${ }^{16}$ WHO search engine WHOLIS, ${ }^{17}$ the BIAM ${ }^{18}$ ROTE LISTE, ${ }^{19}$ and VIDAL ${ }^{20}$ databases was assessed. Key words used were: pyrazinamide, BE, bioavailability, biowaiver, solubility, permeability, dissolution, tuberculosis, excipient, toxicity, polymorphism, and pharmacokinetics.

\section{GENERAL CHARACTERISTICS}

\section{Name}

Pyrazinamide (INN), pyrazinecarboxamide. ${ }^{21,22}$ The structure is shown in Figure 1.

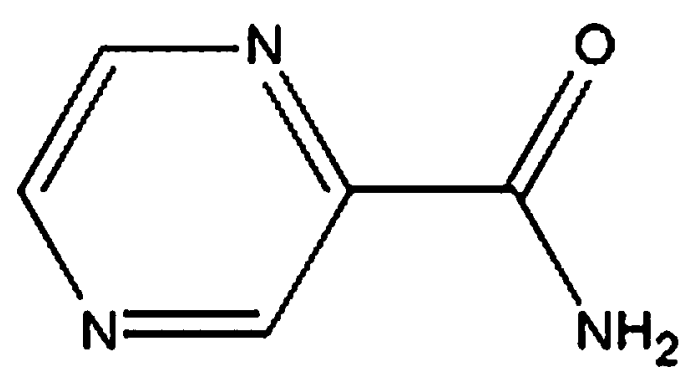

Figure 1. Structure of pyrazinamide, Mw 123.113.

\section{Therapeutic Indications}

Pyrazinamide is one of the key APIs used in the combination treatment of tuberculosis recommended by the WHO. ${ }^{23}$ The standard regime currently calls for initial therapy with isoniazid, rifampicin, pyrazinamide, and ethambutol for the first 2 months, followed by a continuation phase comprising isoniazid and rifampicin which lasts 4 months. Pyrazinamide is used in the initial phase of the treatment for its bactericidal activity against slowly metabolizing bacilli, which results in a low incidence of bacteriological relapse after completion of the chemotherapy regimen. ${ }^{23-25}$

The mechanism of action of pyrazinamide is not fully elucidated. ${ }^{25,26}$ The antimicrobial activity of this synthetic analogue of nicotinamide appears to depend partly on a conversion to its primary metabolite, pyrazinoic acid, in an acidic environment. The metabolite interacts with mycobacterial pyrazinamidase present in in vitro susceptible strains of Mycobacterium tuberculosis. ${ }^{27}$

\section{Therapeutic Index and Toxicity}

The WHO, ${ }^{23}$ the Martindale, ${ }^{28}$ and the British and American Thoracic Society ${ }^{24,29}$ recommend standard daily doses of 25 (20-30), 20-35 (maximum $3 \mathrm{~g}$ ), and $18.2-26.3 \mathrm{mg} / \mathrm{kg}$ (maximum $2 \mathrm{~g}$ ) of pyrazinamide, respectively. Generally, pyrazinamide has been used in doses ranging from 15 to $40 \mathrm{mg} / \mathrm{kg} /$ day. ${ }^{30-32}$ After an oral dose of $1.5 \mathrm{~g}$, peak serum concentrations of $33 \mu \mathrm{g} / \mathrm{mL}$ were reported; ${ }^{28}$ after an oral dose of $27 \mathrm{mg} / \mathrm{kg}$ to healthy volunteers a peak serum concentration of $39 \mu \mathrm{g} /$ $\mathrm{mL}$ was reported. ${ }^{33}$ Different dosing schemes are recommended for children and HIV positive patients. $^{23,24,29,34,35}$

The most common serious adverse drug reaction (ADR) is drug-induced hepatitis. ${ }^{36}$ Toxic effects of pyrazinamide are related to dose and duration of treatment but may occur at any time during 
therapy. ${ }^{37}$ At doses higher than $3 \mathrm{~g} /$ day the incidence of hepatitis increases to $15 \% ;^{24,38,39} \mathrm{a}$ dose of $3 \mathrm{~g}$ was reported to give a peak serum concentration of $59 \mu \mathrm{g} / \mathrm{mL}^{28}$ The incidence of side effects seems to be increased in subpopulations like females, the elderly, those of Asian heritage, patients with renal impairment and HIV patients. ${ }^{40}$ Toman's Tuberculosis recommends that a basic examination of liver function should be conducted before starting treatment with pyrazinamide. ${ }^{34}$ According to the current WHO guideline, the onset of acute liver failure should be managed by immediate interruption of pyrazinamide treatment. ${ }^{23}$ Therefore, patients should be educated to detect the clinical signs of impending acute liver failure. ${ }^{41,42}$ Because of its liver toxicity, pyrazinamide is also contraindicated in patients with latent tuberculosis who are concomitantly taking other potentially liver-toxic drugs, who drink excessive amounts of alcohol, or who have underlying liver disease or a history of isoniazidassociated liver injury. ${ }^{23,28,43-45}$ In these cases the benefits of pyrazinamide therapy should be weighed against possible hepatic ADRs. ${ }^{24}$

Pyrazinamide inhibits the renal excretion of urates, resulting in gout in predisposed patients. $^{27}$ If hyperuricemia is severe or is accompanied by acute gouty arthritis, pyrazinamide should be discontinued. ${ }^{23,24,29}$ The Prescribers' Information, also known as the Summary of Product Characteristics (SmPCs), for most drug products having a marketing authorization (MA) contains appropriate cautionary statements as well as instructions for monitoring of hepatic function. ${ }^{37,43,46}$

\section{CHEMICAL PROPERTIES}

\section{Polymorphs}

Pyrazinamide occurs in four polymorphic forms with different crystal structures: $\alpha-, \beta-, \gamma-$, and $\delta$-pyrazinamide, depending on the solvent and the temperature used in the manufacturing process. ${ }^{47-50}$ Differences in solubility of the four polymorphic forms have not been reported. The pharmacopoeias do not stipulate any specific polymorph.

\section{Solubility}

A summary of the literature solubility data, as well as additional experimental solubility data under physiological conditions and corresponding dose/solubility $(\mathrm{D} / \mathrm{S})$ ratios are presented in Table 1.

\section{Partition Coefficient $(\log P)$}

$\log P$ values of $0.2^{51}$ at $30^{\circ} \mathrm{C}$ and $0.6^{52}$ have been reported for the system octanol/water. However, no detailed information was provided about the

Table 1. Literature Data and New Experimental Solubility Data $(\mathrm{mg} / \mathrm{mL})$ for Pyrazinamide and the Corresponding Dose/Solubility Ratios (D/S) for Two Tablet Strengths

\begin{tabular}{|c|c|c|c|c|c|c|}
\hline \multirow[b]{2}{*}{ Medium, pH } & \multirow[b]{2}{*}{ USP } & \multirow[b]{2}{*}{$\begin{array}{l}\text { Merck } \\
\text { Index }\end{array}$} & \multirow[b]{2}{*}{$\begin{array}{c}\text { New Experimental } \\
\text { Data }\left(37^{\circ} \mathrm{C}\right)\end{array}$} & \multirow[b]{2}{*}{$\begin{array}{c}\text { Florey's } \\
\left(38^{\circ} \mathrm{C}\right)\end{array}$} & \multicolumn{2}{|c|}{$\mathrm{D} / \mathrm{S} \operatorname{Ratio}^{a}(\mathrm{~mL})$} \\
\hline & & & & & $\begin{array}{l}500 \mathrm{mg} \\
\text { Tablet }^{b}\end{array}$ & $\begin{array}{l}400 \mathrm{mg}^{\circ} \\
\text { Tablet }^{c}\end{array}$ \\
\hline Water & 14.9 & & & & 33.6 & 26.8 \\
\hline Water & & 15 & & & 33.3 & 26.7 \\
\hline Water & & & & 26.5 & 18.9 & 15.1 \\
\hline Water & & & & & 78.1 & 62.5 \\
\hline Water $^{d}$ & & & 20.3 & & 24.7 & 19.7 \\
\hline $\mathrm{SGF}_{\mathrm{sp},} \mathrm{pH} 1.2^{d}$ & & & 22.7 & & 22.0 & 17.6 \\
\hline $\begin{array}{l}\text { Phosphate buffer, } \\
\mathrm{pH} 4.5^{d}\end{array}$ & & & 21.6 & & 23.2 & 18.6 \\
\hline $\mathrm{SIF}_{\mathrm{sp}}, \mathrm{pH} 6.8^{d}$ & & & 22.3 & & 22.5 & 18.0 \\
\hline
\end{tabular}


test conditions such as the temperature and $\mathrm{pH}$. A $\log P$ of 1 was observed for the system (butanol/ water) at $30^{\circ} \mathrm{C}^{51} \mathrm{~A}$ computed $X \log P$ of -1.884 is indicated in the PubChem database. ${ }^{15}$ Kasim et al. ${ }^{53}$ obtained a $\log P$ of -0.68 and a $C \log \mathrm{P}^{\circledR}$ of -1.41 using fragmentation methods based on atomic contributions to lipophilicity and the ClogP ${ }^{\circledR}$ program (version 3.0, Biobyte Corp, Claremont, CA, http://www.biobyte.com).

\section{$\mathrm{p} K_{\mathrm{a}}$}

Pyrazinamide is an extremely weak base. A $\mathrm{p} K_{\mathrm{a}}$ value of 0.5 (no temperature specified) has been reported in the literature. ${ }^{54}$

\section{Dosage Form Strengths}

The WHO Essential Medicines List specifies a $400 \mathrm{mg}$ tablet dosage form of pyrazinamide. ${ }^{55}$ Single API dosage forms with an MA in Germany (DE) ${ }^{56}$ Denmark (DK), ${ }^{57}$ Finland (FI), ${ }^{58}$ France (FR), ${ }^{59}$ The Netherlands (NL), ${ }^{60}$ and the USA $(\mathrm{USA})^{61}$ contain $500 \mathrm{mg}$ pyrazinamide.

\section{PHARMACOKINETIC PROPERTIES}

\section{Permeability and Absorption}

No studies investigating the in situ or ex vivo intestinal permeability, absolute bioavailability (BA) or Caco-2 cell studies could be identified in the literature.

It is widely believed that pyrazinamide is nearly fully absorbed from the gut. ${ }^{18,28,62}$ In a study carried out by Ellard ${ }^{32}$ as early as 1969, a urinary recovery of about $40 \%$ after $48 \mathrm{~h}$ was measured after administration of an oral dose of 1500 and $3000 \mathrm{mg}$ to healthy subjects. In another leg of this study, referred to as the Nairobi "crossover study," $34-35 \%$ of an oral dose of $500 \mathrm{mg}$ administered three times a day, $1500 \mathrm{mg}$ once a day or $3000 \mathrm{mg}$ once a day were recovered in the urine of patients with tuberculosis after $24 \mathrm{~h} .{ }^{32} \mathrm{In}$ the same study, using extraction with subsequent coupling color reaction and measurement of the optical density as the analytical method, no API could be detected in the aqueous acetone extracts of feces. Lacroix et al. ${ }^{63}$ found a cumulative urinary excretion of $73 \%$ of the ingested oral dose of pyrazinamide and its metabolites $72 \mathrm{~h}$ after administration of a single oral dose of $27 \mathrm{mg} / \mathrm{kg}$ to healthy subjects. On the basis of this information the authors hypothesized that pyrazinamide possesses a high BA. ${ }^{27,63}$ In children, the absorption of pyrazinamide appears to be delayed and sometimes reduced. ${ }^{64}$

$T_{\max }$ values of $1-2 \mathrm{~h}$ were reported after oral application, values consistent with a moderate to fast rate of absorption. ${ }^{65,66}$ However, rapid absorption does not necessarily indicate that absorption is complete.

Wilkins et al ${ }^{67}$ studied the population pharmacokinetics of three pooled studies encompassing 227 South African patients with tuberculosis. Using NONMEM ${ }^{\mathbb{R}}$ (version V), a one-compartment model with first-order absorption including a zero-order component describing the release from the formulation, the absorption of pyrazinamide was estimated to be bimodally distributed in approximately even portions between two distinct subgroups: those who absorb the compound quickly and those with slow absorption.

Zhu et al. $^{68}$ showed an increase of drug concentration in the blood proportional to administered dose in the range from 0.2 to $3.6 \mathrm{~g} /$ day suggesting that absorption in this dosing range is not dose-dependent. In the "Nairobi Cross-over" study, peak serum concentrations of pyrazinamide and urinary excretion of pyrazinamide and pyrazinoic acid were proportional to the given dose within the investigated range of 500-3000 mg. In the "Extended East African" study Ellard ${ }^{32}$ showed that serum pyrazinamide concentrations were inversely proportional to the body weights of 19 African patients receiving $1500 \mathrm{mg}$ pyrazinamide daily or $3000 \mathrm{mg}$ on alternate days.

\section{Distribution, Metabolism and Excretion}

Pyrazinamide is distributed to most body tissues including lung, kidney, liver, crosses the blood brain barrier ${ }^{18,46,69}$ and penetrates across the membrane of macrophages. ${ }^{70}$

In early studies, pyrazinamide was found to be not bound to plasma proteins in humans, rabbits, and $\operatorname{dog} \mathrm{s}^{51}$ whereas recent literature indicates a plasma protein binding of about 50\% without specifying the assay conditions. ${ }^{37}$ Woo et al. ${ }^{71}$ determined the plasma protein binding of the API to $\alpha$-1-acid glycoprotein (15\%), albumin and whole plasma $(40 \%)$ in vitro. Pyrazinamide is metabolized to its active metabolite, pyrazine-2-carboxylic acid, and subsequently hydroxylated to 5-hydroxypyrazine-2-carboxylic acid. ${ }^{27,72}$ Pyrazinamide metabolism has a moderate interpatient 
variability in adults but median clearance is higher in children and results in a $43 \%$ shorter half-life. ${ }^{73}$ The parent drug, but not its metabolites, are filtered and afterwards actively reabsorbed by the kidneys. ${ }^{27,63}$ Within $24 \mathrm{~h}$, the urinary recovery is about $30-40 \%$ of an oral dose. $^{32,65,72,74}$ The API was not detected in the stools after oral administration. ${ }^{32}$

\section{Food and Other Gastrointestinal Interactions}

Peloquin et al. ${ }^{73}$ investigated the influence of food and antacids on the pharmacokinetics of oral pyrazinamide in healthy volunteers. The study design consisted of a randomized, four-period, crossover study. Single oral doses of $30 \mathrm{mg} / \mathrm{kg}$ of pyrazinamide were administered twice under fasting conditions, once with an aluminummagnesium antacid and once with a high-fat meal and standard dosages of isoniazid, rifampicin, and ethambutol. In all four treatments, a single dose of $30 \mathrm{mg} / \mathrm{kg}$ was administered orally using $500 \mathrm{mg}$ scored tablets (Wyeth-Lederle, Philadelphia, PA) and $240 \mathrm{~mL}$ of tap water. Serum was collected over $48 \mathrm{~h}$ and analyzed by gas chromatography with a mass selective detector. In the fasted state, the variability in AUC, $C_{\max }$ and $t_{\max }$ across the 14 subjects was low. Since the fasted treatment was repeated, intra-subject variability in the pharmacokinetic parameters could be assessed and was found to be low. In the fed versus fasted part of the study, significantly different values for $C_{\max }(-12 \%)$ and delayed absorption $\left(t_{\max }+80 \%\right)$ were measured after administration of a standard, high fat breakfast (792 kcal) compared to the fasted state. Zent et al. compared the BA of pyrazinamide in the fasted state to its BA after ingestion of a carbohydraterich or a high fat meal in 27 adult patients with tuberculosis. ${ }^{68}$ In this study, neither $C_{\max }$, AUC nor $t_{\max }$ were found to be altered by either diet.

Pyrazinamide was shown to be stable in different suspensions: a "simple syrup" mixture and methylcellulose "simple syrup" mixture, both containing a dose of $100 \mathrm{mg} / \mathrm{mL}$ and in a mixture of Pyrazinamide $(10 \mathrm{mg} / \mathrm{mL})$ with Ora-Sweet ${ }^{\mathbb{R}}$ or Ora-Plus ${ }^{\circledR}$ (1:1) with and without cherry syrup over 60 days at $25^{\circ} \mathrm{C}^{75-77}$

In the Peloquin study $30 \mathrm{~mL}$ of an aluminummagnesium antacid (Mylanda ${ }^{\mathbb{R}}$ ) was administered orally $9 \mathrm{~h}$ prior to, at the time of dosing, at bedtime and after meals. ${ }^{73}$ The pharmacokinetics of pyrazinamide were not significantly influenced by the pre-, co-, or postdose administration of the antacid. In an early study (1957) Caccia ${ }^{65}$ showed that activated charcoal totally adsorbs pyrazinamide in diluted urine in vitro.

\section{DOSAGE FORM PERFORMANCE}

\section{Bioavailability and Bioequivalence Studies}

No absolute oral BA of pyrazinamide formulations could be identified in the literature. However, the generic product Pyrazinamide "Lederle," marketed in DE, was approved on the basis of a BE study in 8 volunteers. ${ }^{37} 500 \mathrm{mg}$ Pyrazinamide "Lederle" and $500 \mathrm{mg}$ of the reference product were administered in a crossover design. At a 0.05 significance level, AUC and $C_{\max }$ of the tested pyrazinamide formulations were found not to be significantly different $(p>0.05)$.

Several in vivo and in vitro $\mathrm{BE}$ studies have compared pyrazinamide fixed dose combination formulations to formulations containing pyrazinamide as the only API at the same dose level. The $\mathrm{BE}$ of the product under investigation was confirmed in each case. ${ }^{37,76,78-80}$

\section{Excipients}

Table 2 shows the excipients present in IR solid oral drug products containing pyrazinamide as sole API, with an MA in DE, DK, FI, FR, and NL. It can be inferred that the drug products having an MA in these countries successfully passed an in vivo $\mathrm{BE}$ study. In the third column of this table, the minimum and maximum amount of the listed excipients present per dosage unit in solid oral drug products with an MA in the USA is indicated.

\section{Dissolution}

The current USP specifies for pyrazinamide tablets not less than $(Q \geq) 75 \%$ dissolved within $45 \mathrm{~min}$ in $900 \mathrm{~mL}$ of water at $37^{\circ} \mathrm{C}$ in the paddle apparatus at $50 \mathrm{rpm} .{ }^{81}$ Comparative in vitro dissolution studies of pyrazinamide drug products could not be identified in the literature.

The dissolution behavior of $400 \mathrm{mg}$ pyrazinamide raw powder and two drug products having a MA in DE: Pyrafat ${ }^{\circledR}$ and Pyrazinamide "Lederle," both containing $400 \mathrm{mg}$ of pyrazinamide, were experimentally ${ }^{1}$ assessed according to the WHO

\footnotetext{
${ }^{1}$ Experiments performed at the Institute of Pharmaceutical Technology, J.W. Goethe University, Frankfurt am Main, Germany.
} 
Table 2. Excipients* Present in Pyrazinamide IR Solid Oral Drug Products** with a Marketing Authorization (MA) in Germany (DE), Denmark (DK), Finland (FI), France (FR), The Netherlands (NL), and the Minimal and Maximal Amount of That Excipient Present Pro dosage Unit in Solid Oral Drug Products with an MA in the USA

\begin{tabular}{|c|c|c|}
\hline Excipient & $\begin{array}{c}\text { Drug Products Containing That Excipient } \\
\text { with an MA Granted by } \\
\text { the Named Country }\end{array}$ & $\begin{array}{l}\text { Range Present in Solid Oral } \\
\text { Dosage Forms with an MA in the } \\
\text { USA (mg) }\end{array}$ \\
\hline $\begin{array}{l}\text { Basic butylated methacrylate } \\
\text { copolymer }\end{array}$ & $\mathrm{DE}(1)$ & \\
\hline Calcium stearate & $\mathrm{DE}(2)$ & $0.7-43^{a}$ \\
\hline Castor oil hydrogenated & $\mathrm{FI}(3)$ & $0.93-37.6^{a}$ \\
\hline Cellulose & $\mathrm{DE}(1,2,4)$ & $4.6-1385^{a}$ \\
\hline Copovidone & $\mathrm{DE}(4)$ & $357-854$ \\
\hline Croscarmellose sodium & $\mathrm{DE}(1,4)$ & $2-180$ \\
\hline Crospovidone & $\mathrm{DE}(1,4)$ & $4.4-792^{a}$ \\
\hline Ethanol & $\mathrm{DK}(5)$ & \\
\hline Gelatin & $\mathrm{DE}(2) \mathrm{DK}(6) \mathrm{FI}(3)$ & $1-756^{a}$ \\
\hline Glycerol & $\mathrm{DK}(5) \mathrm{FI}(3)$ & $0.14-198^{b}$ \\
\hline Hypromellose & $\mathrm{DE}(4)$ & $0.8-86$ \\
\hline Lactose & $\mathrm{DE}(2,4) \mathrm{FI}(3)$ & $23-1020^{a}$ \\
\hline Macrogol & $\mathrm{DE}(1,4)$ & $0.12-500^{a}$ \\
\hline Magnesium stearate & $\mathrm{DE}(1,4,7) \mathrm{DK}(5,6) \mathrm{FI}(3) \mathrm{NL}(8)$ & $0.15-401^{a}$ \\
\hline Povidone & DE(1) DK(5) FR (9) NL(8) & $0.17-75$ \\
\hline Silica & DE(4) DK(5) FI(3) NL(8) & $0.65-99$ \\
\hline Sodium starch glycolate & $\mathrm{DE}(2) \mathrm{FI}(3) \mathrm{NL}(8)$ & $2-876^{a}$ \\
\hline Starch & $\mathrm{DE}(2,7) \mathrm{DK}(5,6) \mathrm{FI}(3) \mathrm{FR}(9) \mathrm{NL}(8)$ & $0.44-1135^{a}$ \\
\hline Stearic acid & $\mathrm{DE}(1) \mathrm{FR}(9)$ & $0.9-72^{\alpha}$ \\
\hline Stearic palmitic acid & $\mathrm{DE}(7)$ & \\
\hline Talc & DE(1,2) DK(5,6) FI(3) FR (9) NL(8) & $0.26-220^{a}$ \\
\hline
\end{tabular}

1, PZAHefa Filmtabletten (Mono); 2, Pyrazinamid $500 \mathrm{mg}$ JENAPHARM $^{\circledR}$ Tabletten (Mono); 3, Tisamid 500 mg tabletti; 4, Pyrafat ${ }^{\circledR} 500 \mathrm{mg}$ Filmtabletten (Mono); 5, Pyrazinamid SAD, tabletter $500 \mathrm{mg}$; 6, Pyrazinamid "Medic", tabletter $500 \mathrm{mg}$; 7, "Pyrazinamid, Lederle" Tabletten (Mono); 8, Pyrazinamide CF 500 mg, tabletten; 9, PIRILENE 500 mg cp séc.

${ }^{*}$ Colourants are not included.

${ }^{* *}$ Drug products containing more than one API are excluded.

${ }^{a}$ The upper range value reported is unusually high for solid oral dosage forms and the authors doubt its correctness .

${ }^{b}$ The authors doubt the correctness of these data. Such amounts are normally present in a soft gelatin capsules, but not in capsules, as indicated by FDA Inactive Ingredients Database.

requirements for $\mathrm{BE}^{2,82}$ Within $10 \mathrm{~min}$, almost $95 \%$ of the powder and at least $88 \%$ of the labeled amount of API of the two tablet formulations were dissolved in USP $\mathrm{SGF}_{\mathrm{sp}} \mathrm{pH} 1.2$, in USP $\mathrm{SIF}_{\mathrm{sp}} \mathrm{pH}$ 6.8 and in a phosphate buffer $\mathrm{pH}$ 4.5. These results were confirmed using a slightly modified methodology with commercially available raw materials from the South African market from three different sources. (Dekker T.G. 2006. personal communication).

\section{DISCUSSION}

\section{Solubility}

The solubility values found in the literature were not assessed under the conditions specified for the BCS classification of drugs. ${ }^{2,82-84}$ For example, studies were done at room temperature instead of $37^{\circ} \mathrm{C}$, water was used as the medium and/or the $\mathrm{pH}$ was not confirmed to remain constant during the solubility determination. To obtain more reliable data, new solubility determinations were carried out. The solubility of pyrazinamide at $37^{\circ} \mathrm{C}$ was virtually constant (at about $22 \mathrm{mg} / \mathrm{mL}$ ) over the $\mathrm{pH}$ range studied, as illustrated in Table 1 . All determinations, calculated for the highest available tablet strengths on the German market and on the WHO Essential Medicines List, resulted in $\mathrm{D} / \mathrm{S}$ ratios of $20 \mathrm{~mL}$ or lower, far below the critical limit of $250 \mathrm{~mL}$, see Table 1 .

According to the current BCS guidelines, an API is highly soluble if the volume required to dissolve the highest dosage strength is less than or equal to $250 \mathrm{~mL} .^{2,82-84}$ Thus, pyrazinamide can be clearly classified as highly soluble. As differences in solubility of the polymorphic forms have not 
been reported and pharmacopoeias do not stipulate any specific polymorph, it is not expected that for any specific polymorph that conclusion would be different.

\section{Permeability}

The only available information regarding pyrazinamide's permeability were taken from urinary recovery studies. Urinary recoveries of $40 \%$ of the oral dose after $48 \mathrm{~h}$, using a questionable detection method based on extraction and subsequent color reactions, ${ }^{32}$ and of $73 \%$ after $72 \mathrm{~h}$, using a HPLC analytical method with fluorimetric detection for quantification, were reported. ${ }^{63}$ But, since pyrazinamide as parent drug is actively reabsorbed by the kidneys, it can be assumed that the parent molecule has a longer plasma half-life. ${ }^{65,70}$ Therefore the collection period of $72 \mathrm{~h}$ might be not sufficiently long enough to measure the complete urinary recovery. As a result, no firm conclusion can be drawn about the permeability classification of pyrazinamide.

\section{BCS Classification}

According to the present Guidances pyrazinamide meets the criteria for highly soluble. ${ }^{2,82-84}$ Data on its permeability are inconclusive but suggest this API to be BCS Class III with moderate permeability properties. Kasim et al. ${ }^{53}$ and Lindenberg et al. ${ }^{85}$ provisionally classified pyrazinamide as a BCS Class III drug, using $\log \mathrm{P} / \mathrm{C} \log \mathrm{P}^{\circledR}$ and literature BA data, respectively. Because of the lack of definitive literature data for the fraction absorbed orally, the WHO Guideline classified the permeability of pyrazinamide as "borderline III/I."2,82

Currently, the FDA and the EMEA do not accept biowaivers for BCS Class III APIs. ${ }^{83,84}$ The recent WHO guidance extended the possibility of a biowaiver approval to Class III APIs under certain conditions. As a Class III compound, pyrazinamide is therefore a potential candidate for biowaiving according to the WHO guidance.

\section{Surrogate Techniques for In Vivo BE Testing}

Pyrazinamide is highly soluble, with the pure powder as well as the pyrazinamide drug products with an MA in DE showing very rapid dissolution. Furthermore, bioinequivalence of pyrazinamide formulations has not been reported either in vivo or in vitro in the literature and appears unlikely to occur for this very soluble API. Hence, the stricter dissolution methodology for biowaiving of BCS Class III drugs according the WHO guidance, that is, very rapid dissolution of the test and the comparator over the $\mathrm{pH}$ range of $1.2-6.8,{ }^{2,82}$ should be capable of detecting a bioinequivalent test product. A caveat to these arguments is that in vitro dissolution tests are not able to detect excipient effects on permeability and/or GI transit time that may cause bioinequivalence.

\section{Risks with Respect to Excipient and Manufacturing Variations}

Studies describing BA problems, interactions of pyrazinamide with excipients or bioinequivalence of pyrazinamide products could not be found in the open literature. All in vivo $\mathrm{BE}$ studies of pyrazinamide in fixed dose combinations versus formulations containing pyrazinamide as the only API confirmed the $\mathrm{BE}$ of the products under investigation. ${ }^{76,78-80}$

Since there are no reports of bioinequivalent drug products in the open literature, and $\mathrm{BE}$ of drug products differing in composition with respect to the excipients can be assumed by virtue of their MA in a number of countries, the risk of bioinequivalence of pyrazinamide IR dosage forms appears to be low. The risk of bioinequivalence caused by an excipient interaction can be further reduced by using in the test product only excipients present in drug products having a MA in an ICH or associated country, as listed as a guide in Table $2 .{ }^{2}$

\section{Patient Risks Associated with Bioinequivalence}

When an API has a narrow therapeutic index (NTI), this precludes the possibility of a biowaiver. The FDA guidance ${ }^{84}$ excludes APIs having a NTI for biowaivers, defining NTI APIs as those subject to therapeutic drug concentration or pharmacodynamic monitoring, and/or where product labeling indicates a narrow therapeutic range designation. The EMEA guidance ${ }^{83}$ provides a general statement indicating that when plasma concentrations are critical, this needs to be taken into consideration; the WHO guidance ${ }^{2}$ states that pharmaceutical products containing an API with

${ }^{2}$ CFR name: narrow therapeutic ratio. 
NTI always should be tested in vivo, because the risk to the patient resulting from a possible incorrect $\mathrm{BE}$ decision using the biowaiver procedure is considered too high with these kinds of APIs. According to the Code of Federal Regulations (CFR), an API has a $\mathrm{NTI}^{2}$ when there is less than a twofold difference between the minimum toxic concentrations and minimum effective concentrations in the blood, and/or safe and effective use of the drug products requires careful dosage titration and patient monitoring. ${ }^{86}$ With respect to the first criterion: the minimum toxic concentration of pyrazinamide can be taken as $59 \mu \mathrm{g} / \mathrm{mL}$, see above. Assuming that the peak serum concentrations of 33 and $39 \mu \mathrm{g} / \mathrm{mL}$ reported above, for doses of $1.5 \mathrm{~g}$ and $27 \mathrm{mg} / \mathrm{kg}$, respectively, are well above the minimum effective concentrations, pyrazinamide is borderline or below the first CFR criterion for NTI. However, according to the CFR's second criterion it would be considered NTI.

Due to the borderline NTI characteristics of pyrazinamide, it is worth looking at the particular risks associated with pyrazinamide drug products more in detail. The first consideration is the consequence of an inadvertently low AUC and/or low $C_{\text {max }}$. The peak concentration is not important for the bactericidal effect. AUC is important, but the wide range of recommended doses and serum concentrations indicate that pyrazinamide's doseresponse curve is not steep. So under-dosing poses comparatively little risk for the patient. The second consideration is the consequence of inadvertently high $\mathrm{AUC}$ and/or $C_{\text {max }}$. Patients under pyrazinamide treatment are monitored primarily because of the risk of hepatic toxicity. Serious, dose-dependent hepatic ADRs theoretically could occur as a consequence of a higher AUC and/or $C_{\text {max }}$. The therapeutic dose ( $20-30 \mathrm{mg} / \mathrm{kg} /$ day) and the dose at which the risk of hepatic ADR increases, $\geq 43 \mathrm{mg} / \mathrm{kg} /$ day, differ by a factor of around two. Based on the evidence presented, it is highly unlikely that a test product would show twice the AUC and/or $C_{\max }$ of a pharmaceutically equivalent comparator when both are very rapidly dissolving and the test drug product is formulated exclusively with excipients that have been used in pyrazinamide formulations which have passed an in vivo $\mathrm{BE}$ study. When, in addition, patients treated with the test product are also regularly monitored for hepatic toxicity, the additional risk associated with the very small risk of an inadvertently incorrect $\mathrm{BE}$ decision can be deemed acceptable. Most SmPCs for pyrazinamide pro- ducts contain such a warning and have instructions for regular hepatic monitoring. ${ }^{37,43,46}$

\section{CONCLUSION}

A biowaiver can be recommended for IR solid oral dosage when the test product (a) contains only excipients present in pyrazinamide IR solid oral drug products approved in ICH or associated countries, for example those presented in this article in Table 2, and (b) only in amounts in normal use in IR solid oral dosage forms, (c) the test product complies with the criteria for very rapidly dissolving ${ }^{2,82}$ and (d) the $\mathrm{SmPC}$ of the test product indicates the necessity to test liver function prior to initiating pyrazinamide therapy, to continue regular monitoring during therapy, and provides an adequate description of the symptoms of impending acute liver failure. If not all of these conditions can be fulfilled, BE should be established on the basis of an in vivo pharmacokinetic BE study.

\section{ACKNOWLEDGMENTS}

Dr. M. Flegel, Riemser Arzneimittel AG, Schiffweiler and Dr. Kunitz, Lungenklinik Heckeshorn, Berlin, both Germany, and Kik Groot, RIVM, are acknowledged for providing literature data, for detailed information of the ADRs of pyrazinamide, and producing Table 2, respectively. Prof. T. Dekker is acknowledged for sharing dissolution data on pyrazinamide.

\section{REFERENCES}

1. Vogelpoel H, Welink J, Amidon GL, Junginger HE, Midha KK, Moller H, Olling M, Shah VP, Barends DM. 2004. Biowaiver monographs for immediate release solid oral dosage forms based on biopharmaceutics classification system (BCS) literature data: Verapamil hydrochloride, propranolol hydrochloride, and atenolol. J Pharm Sci 33:1945-1956.

2. WHO. 2006. Proposal to waive in vivo bioequivalence requirements for WHO Model List of Essential Medicines immediate-release, solid oral dosage forms. Technical Report Series, No937, 40th Report, Annex 8 of WHO Expert committee on specifications for pharmaceutical preparations http:// whqlibdoc.who.int/trs/WHO_TRS_937_eng.pdf. 
3. Kalantzi L, Reppas C, Dressman JB, Amidon GL, Junginger HE, Midha KK, Shah VP, Stavchansky SA, Barends DM. 2006. Biowaiver monographs for immediate release solid oral dosage forms: Acetaminophen (paracetamol). J Pharm Sci 95:4-14.

4. Manzo RH, Olivera ME, Amidon GL, Shah VP, Dressman JB, Barends DM. 2006. Biowaiver monographs for immediate release solid oral dosage forms: Amitriptyline hydrochloride. J Pharm Sci 95:966-973.

5. Verbeeck RK, Junginger HE, Midha KK, Shah VP, Barends DM. 2005. Biowaiver monographs for immediate release solid oral dosage forms based on biopharmaceutics classification system (BCS) literature data: Chloroquine phosphate, chloroquine sulfate, and chloroquine hydrochloride. J Pharm Sci 94:1389-1395.

6. Jantratid E, Prakongpan S, Dressman JB, Amidon GL, Junginger HE, Midha KK, Barends DM. 2006. Biowaiver monographs for immediate release solid oral dosage forms: Cimetidine. J Pharm Sci: 95:974984.

7. Becker C, Dressman JB, Amidon GL, Junginger HE, Kopp S, Midha KK, Shah VP, Stavchansky S, Barends DM. 2007. Biowaiver monographs for immediate release solid oral dosage forms: Ethambutol dihydrochloride. J Pharm Sci. Published online.

8. Potthast H, Dressman JB, Junginger HE, Midha KK, Oeser H, Shah VP, Vogelpoel H, Barends DM. 2005. Biowaiver monographs for immediate release solid oral dosage forms: Ibuprofen. J Pharm Sci 94:2121-2131.

9. Becker C, Dressman JB, Amidon GL, Junginger HE, Kopp S, Midha KK, Shah VP, Stavchansky S, Barends DM. 2006. Biowaiver monographs for immediate release solid oral dosage forms: Isoniazid. J Pharm Sci 96:522-531.

10. Vogt M, Derendorf H, Kramer J, Junginger HE, Midha KK, Shah VP, Stavchansky S, Dressman JB, Barends DM. 2007. Biowaiver monographs for immediate release solid oral dosage forms: Prednisolone. J Pharm Sci 96:27-37.

11. Vogt M, Derendorf H, Kramer J, Junginger HE, Midha KK, Shah VP, Stavchansky S, Dressman JB, Barends DM. 2007. Biowaiver monographs for immediate release solid oral dosage forms: Prednisone. J Pharm Sci 96:1480-1489.

12. Kortejarvi H, Yliperttula M, Dressman JB, Junginger HE, Midha KK, Shah VP, Barends DM. 2005. Biowaiver monographs for immediate release solid oral dosage forms: Ranitidine hydrochloride. J Pharm Sci 94:1617-1625.

13. International Pharmaceutical Federation FIP. Working Group on Biopharmaceutics Classification System (BCS). http://www.fip.org/www2/sciences/ index.php?page=pharmacy_sciences \& pharmacy sciences $=$ sciences_bioavail_groupbcs.
14. National Library of Medicine (NLM) and the National Institutes of Health, NCBI, PubMed. 2006. NCBI, http://www.pubmed.gov.

15. National Library of Medicine (NLM) NCBI PubChem Compound http://www.ncbi.nlm.nih.gov/ entrez/query.fcgi?db=pccompound.

16. MedicinesComplete. 2006. Pharmaceutical Press, London, http://www.medicinescomplete.com/mc/.

17. World Health Organization (WHO). Library \& Information Networks for Knowledge Database (WHOLIS). http://dosei.who.int/uhtbin/cgisirsi/ Mon+Jan+10+13:45:18+MET+2005/0/49.

18. VIDAL BIAM database: Pyrazinamide (French). http://www.biam2.org.

19. Rote Liste ${ }^{\mathbb{R}}$ Service GmbH Frankfurt/Main: ROTE LISTE $^{\circledR}$ Arzneimittelsverzeichnis für Deutschland (einschließlich EU-Zulassungen und bestimmter Medizinprodukte) (German). http://www.rote-liste. de/Online.

20. VIDAL L'information de référence sur les produits de santé (French). http://www.vidal.fr.

21. World Health Organization (WHO). 2004. The International Pharmacopoeia. In Third edition, General Methods of Analysis, Quality Specifications for Pharmaceutical Substances, Excipients and Dosage Forms. http://www.who.int/bookorders/anglais/detart1.jsp?sesslan=1 \& codlan=1 \& codcol $=15 \& \operatorname{codcch}=4091$.

22. World Health Organization (WHO). Guidance on INN. http://www.who.int/medicines/services/inn/ innquidance/en/.

23. World Health Organization (WHO). 2003. Revision approved June 2004. Treatment of Tuberculosis: Guidelines for national programmes. http:/www. emro.who.int/stb/media/pdf/Guidelines2003.pdf.

24. AHFS Drug Information. Pharmaceutical Press, London: Electronic version: 2007. (ASHP) TASoHSP. Pharmaceutical Press, London. http://www. medicinescomplete.com/mc/ahfs/current/.

25. Steele MA, Des Prez RM. 1988. The role of pyrazinamide in tuberculosis chemotherapy. Chest 34:845-850.

26. Heifets LB, Flory MA, Lindholm-Levy PJ. 1989. Does pyrazinoic acid as an active moiety of pyrazinamide have specific activity against Mycobacterium tuberculosis? Antimicrob Agents Chemother 33:1252-1254.

27. Weiner IM, Tinker JP. 1972. Pharmacology of pyrazinamide: Metabolic and renal function studies related to the mechanism of drug-induced urate retention. J Pharmacol Exp Ther 180:411-434.

28. Martindale. Martindale: The Complete Drug Reference, electronic version. 2006. Pharmaceutical Press, London. http://www.medicinescomplete.com/ $\mathrm{mc} / \mathrm{martindale} / 2006 /$.

29. Treatment of Tuberculosis, American Thoracic Society, CDC, and Infectious Diseases Society of America-United States, 2003. 2003. http:// 
www.cdc.gov/mmwr/preview/mmwrhtml/rr5211a1. htm.

30. Blumberg HM. 2004. Treatment of latent tuberculosis infection: Back to the beginning. Clin Infect Dis 93:1772-1775.

31. Blumberg HM, Leonard MK, Jr., Jasmer RM. 2005. Update on the treatment of tuberculosis and latent tuberculosis infection. JAMA 293:2776-2784.

32. Ellard GA. 1969. Absorption, metabolism and excretion of pyrazinamide in man. Tubercle 50:144-158.

33. Lacroix C, Guyonnaud C, Chaou M, Duwoos H, Lafont O. 1988. Interaction between allopurinol and pyrazinamide. Eur Respir J 1:807-811.

34. World Health Organization (WHO). 2004. Toman's Tuberculosis. Case Detection, Treatment and Monitoring. Second Edition. http://whqlibdoc.who.int/ publications/2004/9241546034.pdf.

35. Update: Adverse event data and revised American Thoracic Society/CDC recommendations against the use of rifampin and pyrazinamide for treatment of latent tuberculosis infection-United States, 2003. 2003. http://www.ncbi.nlm.nih.gov/entrez/ query.fcgi?cmd=Retrieve $\& \mathrm{db}=$ PubMed $\& \mathrm{dopt}=$ Citation \& list_uids $=12904741$.

36. Taneja DP, Kaur D. 1990. Study on hepatotoxicity and other side-effects of antituberculosis drugs. J Indian Med Assoc 88:278-280.

37. RIEMSER Fachinformation PYRAZINAMID "Lederle" (German).

38. Chan-Yeung M, Noertjojo K, Leung CC, Chan SL, Tam CM. 2003. Prevalence and predictors of default from tuberculosis treatment in Hong Kong. Hong Kong Med J 9:263-268.

39. Leung CC, Law WS, Chang KC, Tam CM, Yew WW, Chan CK, Wong MY. 2003. Initial experience on rifampin and pyrazinamide vs isoniazid in the treatment of latent tuberculosis infection among patients with silicosis in Hong Kong. Chest 124: 2112-2118.

40. Yee D, Valiquette C, Pelletier M, Parisien I, Rocher I, Menzies D. 2003. Incidence of serious side effects from first-line antituberculosis drugs among patients treated for active tuberculosis. Am J Respir Crit Care Med 167:1472-1477.

41. WHO. Pharmaceuticals Newsletter No. 1. 2002. Excerpts from the report of the 24th Annual Meeting of the National Centres participating in the WHO Programme for International Drug Monitoring. World Health Organization (WHO). http:// www.who.int/medicines/publications/newsletter/en/ news2002_1.pdf.

42. Duc Vu P, Lynn Macdonald BSP. Bureau of Licensed Product Assessment 2001. Antitubercular drugs (isoniazid, rifampin and pyrazinamide): Hepatobiliary reactions. http://www.hc-sc.gc.ca/ dhp-mps/alt_formats/hpfb-dgpsa/pdf/medeff/carn-bcei_ v11n4_e.pdf.
43. FATOL Fachinformation Pyrafat ${ }^{\circledR} 100 \mathrm{mg}$ Tabletten (German)

44. Stout JE. 2004. Safety of rifampin and pyrazinamide for the treatment of latent tuberculosis infection. Expert Opin Drug Saf 3:187-198.

45. Stout JE, Engemann JJ, Cheng AC, Fortenberry ER, Hamilton CD. 2003. Safety of 2 months of rifampin and pyrazinamide for treatment of latent tuberculosis. Am J Respir Crit Care Med 167:824 827.

46. SANOFI-AVENTIS Pirilène ${ }^{\circledR}$ pyrazinamide (French), VIDALPro (L'intégralité de l'information officielle (issue des RCP de l'Afssaps) sur l'ensemble des médicaments commercialisés en France).

47. Ro G, Sorum H. 1972. Crystal and Molecular Structure of Beta-Pyrazincarboxamide. Acta Crystall B Stru B28:991-998.

48. Ro G, Sorum H. 1972. Crystal and molecular structure of delta-pyrazincarboxamide. Acta Crystall B Stru B28:1677-1684.

49. Takaki Y, Sasada Y, Watanabe T. 1960. The crystal structure of alpha-pyrazinamide. Acta Crystallogr 13:693-702.

50. Tamura C, Sasada Y, Kuwano H. 1961. Crystallographic data of carboxylic acids and carboxyamides of picoline and pyrazine derivatives. Acta Crystallogr 14:693

51. Felder E, Pitre D. 1977. Analytical Profiles of Drug Substances and Excipients, K. Florey's/ H.G. Brittain, Oxford University Press, 12; 434461.

52. The Merck Index, 13th edition. 2005.

53. Kasim NA, Whitehouse M, Ramachandran C, Bermejo M, Lennernas H, Hussain AS, Junginger HE, Stavchansky SA, Midha KK, Shah VP, Amidon GL. 2004. Molecular properties of WHO essential drugs and provisional biopharmaceutical classification. Mol Pharm 1:85-96.

54. Clarke's Analysis of Drugs and Poisons, Pharmaceutical Press, London: Electronic version: 2006. Pharmaceutical Press, London. http://www.medicinescomplete.com/mc/clarke/2006/.

55. World Health Organization (WHO). 2005. Essential Medicines WHO Model List (EML), 14th edition, (revised version march 2005). http://whqlibdoc. who.int/hq/2005/a87017_eng.pdf.

56. Rote Liste ${ }^{\mathbb{R}}$ Service Gmb̄H Frankfurt/Main: ROTE LISTE $^{\circledR}$ Arzneimittelsverzeichnis für Deutschland (einschließlich EU-Zulassungen und bestimmter Medizinprodukte) (German) (assessed 05-07-2007). http://www.rote-liste.de/Online.

57. The Danish Medicines Agency: An agency under the Ministry of the Interior and Health. (Assessed 05-07-2007). 2007. www.dkma.dk.

58. National Agency for Medicines, Helsinki, Finland: The National Agency for Medicines responsibilities are to maintain and promote the safety and safe use 
of medicinal products, medical devices and blood products. (Assessed 04-07-2007). www.nam.fi.

59. VIDAL L'information de référence sur les produits de santé (French) (assessed 06-07-2007). http:// www.vidal.fr.

60. College ter Beoordeling van Geneesmiddelen, CBG MEB, Medicines Evaluation Board (Dutch). (Assessed 06-07-2007). http://www.cbg-meb.nl/.

61. U.S. Department of Health and Human Services Food and Drug Administration, Center for Drug Evaluation and Research, Office of Pharmaceutical Science, Office of Generic Drugs: Electronic Orange Book, approved Drug Products with Therapeutic Equivalence Evaluations; electronic source: 2006. NCBI. http://www.fda.gov/cder/ob/.

62. Holdiness MR. 1984. Clinical pharmacokinetics of the antituberculosis drugs. Clin Pharmacokinet 19:511-544.

63. Lacroix C, Hoang TP, Nouveau J, Guyonnaud C, Laine G, Duwoos H, Lafont O. 1989. Pharmacokinetics of pyrazinamide and its metabolites in healthy subjects. Eur J Clin Pharmacol 36:395400.

64. Peloquin CA. 2002. Therapeutic drug monitoring in the treatment of tuberculosis. Drugs 62:21692183.

65. Caccia PA. 1957. Spectrophotometic determination of pyrazinamide blood concentrations and excretion through the kidneys. Am Rev Tuberc 75:105110.

66. Perlman DC, Segal Y, Rosenkranz S, Rainey PM, Peloquin CA, Remmel RP, Chirgwin K, Salomon N, Hafner R. 2004. The clinical pharmacokinetics of pyrazinamide in HIV-infected persons with tuberculosis. Clin Infect Dis 38:556-564.

67. Wilkins JJ, Langdon G, McIlleron H, Pillai GC, Smith PJ, Simonsson US. 2006. Variability in the population pharmacokinetics of pyrazinamide in South African tuberculosis patients. Eur J Clin Pharmacol 62:727-735.

68. Zent C, Smith P. 1995. Study of the effect of concomitant food on the bioavailability of rifampicin, isoniazid and pyrazinamide. Tuber Lung Dis 76:109-133.

69. Forgan-Smith R, Ellard GA, Newton D, Mitchison DA. 1973. Pyrazinamide and other drugs in tuberculous meningitis. Lancet 302:374.

70. Stottmeier KD, Beam RE, Kubica GP. 1968. The absorption and excretion of pyrazinamide. I. Preliminary study in laboratory animals and in man. Am Rev Respir Dis 98:70-74.

71. Woo J, Cheung W, Chan R, Chan HS, Cheng A, Chan K. 1996. In vitro protein binding characteristics of isoniazid, rifampicin, and pyrazinamide to whole plasma, albumin, and alpha-1-acid glycoprotein. Clin Biochem 29:175-177.

72. Roboz J, Suzuki R, Yu TF. 1978. Mass fragmentographic determination of pyrazinamide and its metabolites in serum and urine. J Chromatogr 147:337-347.

73. Peloquin CA, Bulpitt AE, Jaresko GS, Jelliffe RW, James GT, Nix DE. 1998. Pharmacokinetics of pyrazinamide under fasting conditions, with food, and with antacids. Pharmacotherapy 18:12051211.

74. Ratti B, Toselli A, Beretta E, Bernareggi A. 1982. HPLC assay of pyrazinoic acid in human plasma in the presence of pyrazinamide and other antituberculosis drugs using an automatic sampler. Farmaco [Prat] 37:226-234.

75. Allen LV, Jr., Erickson MA. 1998. Stability of bethanechol chloride, pyrazinamide, quinidine sulfate, rifampin, and tetracycline hydrochloride in extemporaneously compounded oral liquids. Am J Health Syst Pharm 55:1804-1809.

76. Gurumurthy P, Ramachandran G, Vijayalakshmi S, Kumar AK, Venkatesan P, Chandrasekaran V, Vjayasekaran V, Kumaraswami V, Prabhakar R. 1999. Bioavailability of rifampicin, isoniazid and pyrazinamide in a triple drug formulation: Comparison of plasma and urine kinetics. Int $\mathrm{J}$ Tuberc Lung Dis 3:119-125.

77. Nahata MC, Morosco RS, Peritore SP. 1995. Stability of pyrazinamide in two suspensions. Am J Health Syst Pharm 52:1558-1560.

78. Agrawal S, Singh I, Kaur KJ, Bhade SR, Kaul CL, Panchagnula R. 2002. Bioequivalence assessment of rifampicin, isoniazid and pyrazinamide in a fixed dose combination of rifampicin, isoniazid, pyrazinamide and ethambutol vs. separate formulations. Int J Clin Pharmacol Ther 40:474481.

79. Panchagnula R, Kaur KJ, Singh I, Kaul CL. 2000. Bioequivalence of rifampicin when administered as a fixed-dose combined formulation of four drugs versus separate formulations. Methods Find Exp Clin Pharmacol 22: 689-694.

80. Panchagnula R, Sancheti P, Rungta S, Agrawal S, Kaul CL. 2003. Evaluation of bioequivalence of isoniazid and pyrazinamide in three and four drugs fixed dose combinations using WHO simplified protocol. Pharmacol Res 42:383-387.

81. U.S. Pharmacopeia (USP30-NRF25), 2007. pp 3079-3080.

82. WHO. 2006. Multisource (generic) pharmaceutical products: Guidelines on registration requirements to establish interchangeability, Technical Report Series, No937, 40th Report, Annex 7 of WHO Expert committee on specifications for pharmaceutical preparations. http://whqlibdoc.who.int/trs/ WHO_TRS_937_eng.pdf.

83. European Medicines Evaluation Agency (EMEA). Committee for Proprietary Medicinal Products (CPMP). 2001. Note for Guidance on the Investigation of Bioavailability and Bioequivalence. http:// www.emea.eu.int/pdfs/human/ewp/140 198en.pdf. 
84. U.S. Department of Health and Human Services Food and Drug Administration Center for Evaluation and Research (CDER). 2000. Guidances for industry: Waiver of in vivo bioavailability and bioequivalence studies for immediate-release solid oral dosage forms based on a Biopharmaceutics Classification System. http://www.fda.gov/CDER/GUIDANCE/3618fnl.pdf.

85. Lindenberg M, Kopp S, Dressman JB. 2004. Classification of orally administered drugs on the World Health Organization Model list of Essential
Medicines according to the biopharmaceutics classification system. Eur J Pharm Biopharm 58:265278.

86. FDA. 2006. Code of Federal regulations. Title 21 Part 320. Bioavailability and bioequivalence requirements. Subpart B: Procedures for Determining the Bioavailability or Bioequivalence of Drug Products Sec. 320.33: Criteria and evidence to assess actual or potential bioequivalence problems. http://www. accessdata.fda.gov/scripts/cdrh/cfdocs/ cfCFR/CFRSearch.cfm?fr $=320.33$. 